\title{
Empirical Comparison of some Iteration Methods in the Class of Quasi-Contractive Operators
}

\author{
Adesanmi Alao Mogbademu \\ Department of Mathematics, \\ Faculty of Sicnece, \\ University of Lagos, Nigeria.
}

\author{
Victor Odumuyiwa \\ Department of Computer Science, \\ Faculty of Science, \\ University of Lagos, Nigeria.
}

\begin{abstract}
In this paper, a new modified two-step iterative method for approximating fixed points of quasi-contractive operators is presented. It is demonstrated with some examples using an empirical approach that this iteration method performs better than some well known iterations for quasi-contractive operators satisfying Zamfirescus conditions.
\end{abstract}

\section{General Terms}

Mann iteration; Ishikawa iteration; Common fixed point; Banach spaces.

\section{Keywords}

Zamifirecu operators; Quasi-contractive operators; Metrizable spaces.

\section{INTRODUCTION}

Approximation of fixed point of nonlinear operators is one of the most important problems in numerical analysis. Much attention has been given to developing several iterative methods to approximate fixed point of some classess of quasi-contractive operators, see[1-13] and the references therein. Let us consider some well known iterative methods that have been used by several researchers to approximate fixed points of quasi-contractive operators.

One-step iterative method(due to Mann [7]):

Step 1. For initial guess $x_{0}$, a tolerance $\varepsilon>0$, for iterations $\mathrm{n}$, set $k=0$.

Step 2. Calculate $x_{1}, x_{2}, \ldots$, such that

$x_{n+1}=\left(1-b_{n}\right) x_{n}+b_{n} T x_{n}, n \geq 0$,

where $\left\{b_{n}\right\}_{n=0}^{\infty}$ is a sequence in $[0,1]$.

Step 3. For given $\varepsilon>0$, if $\left|x_{k+1}-x_{k}\right|<\varepsilon$, or $k>n$, then stop.

Step 4. Set $k=k+1$ and go to Step 2 .

Two-step iterative method (due to Ishikawa [6]):

Step 1. For initial guess $x_{0}$, a tolerance $\varepsilon>0$, for iterations $\mathrm{n}$, set $k=0$.

Step 2. Calculate $x_{1}, x_{2}, \ldots$, such that

$z_{n}=\left(1-b_{n}^{\prime}\right) x_{n}+b_{n}^{\prime} T x_{n}$

$x_{n+1}=\left(1-b_{n}\right) x_{n}+b_{n} T z_{n}, n \geq 0$,

where $\left\{b_{n}\right\}_{n=0}^{\infty},\left\{b_{n}^{\prime}\right\}_{n=0}^{\infty}$ are sequences in $[0,1]$.

Step 3. For given $\varepsilon>0$, if $\left|x_{k+1}-x_{k}\right|<\varepsilon$, or $k>n$, then stop.

Step 4. Set $k=k+1$ and go to Step 2 .

New two-step iterative method (due to Yildirim et al. [12]):
Step 1. For initial guess $x_{0}$, a tolerance $\varepsilon>0$, for iterations $n$, set $k=0$.

Step 2. Calculate $x_{1}, x_{2}, \ldots$, such that

$z_{n}=\left(1-b_{n}^{\prime}\right) x_{n}+b_{n}^{\prime} T x_{n}$

$x_{n+1}=\left(1-b_{n}\right) z_{n}+b_{n} T z_{n}, n \geq 0$,

where $\left\{b_{n}\right\}_{n=0}^{\infty},\left\{b_{n}^{\prime}\right\}_{n=0}^{\infty}$ are sequences in $[0,1]$.

Step 3. For given $\varepsilon>0$, if $\left|x_{k+1}-x_{k}\right|<\varepsilon$, or $k>n$, then stop.

Step 4. Set $k=k+1$ and go to Step 2 .

Two-step iterative method (due to Agarwal et al. [2]):

Step 1. For initial guess $x_{0}$, a tolerance $\varepsilon>0$, for iterations $\mathrm{n}$, set $k=0$.

Step 2. Calculate $x_{1}, x_{2}, \ldots$, such that

$z_{n}=\left(1-b_{n}^{\prime}\right) x_{n}+b_{n}^{\prime} T x_{n}$

$x_{n+1}=\left(1-b_{n}\right) T z_{n}+b_{n} T z_{n}, n \geq 0$,

where $\left\{b_{n}\right\}_{n=0}^{\infty},\left\{b_{n}^{\prime}\right\}_{n=0}^{\infty}$ are sequences in $[0,1]$.

Step 3. For given $\varepsilon>0$, if $\left|x_{k+1}-x_{k}\right|<\varepsilon$, or $k>n$, then stop.

Step 4. Set $k=k+1$ and go to Step 2 .

We suggest here a new modified two-step iterative method:

New modified two-step iterative method:

Step 1. For initial guess $x_{0}$, a tolerance $\varepsilon>0$, for iterations $\mathrm{n}$, set $k=0$.

Step 2. Calculate $x_{1}, x_{2}, \ldots$, such that

$z_{n}=\left(1-b_{n}^{\prime}\right) x_{n}+b_{n}^{\prime} T x_{n}$

$x_{n+1}=\left(1-b_{n}\right) S x_{n}+b_{n} T z_{n}, n \geq 0$,

where $\left\{b_{n}\right\}_{n=0}^{\infty},\left\{b_{n}^{\prime}\right\}_{n=0}^{\infty}$ are sequences in $[0,1]$.

Step 3. For given $\varepsilon>0$, if $\left|x_{k+1}-x_{k}\right|<\varepsilon$, or $k>n$, then stop.

Step 4. Set $k=k+1$ and go to Step 2 .

Remarks 1.2. (i) we note that the new modified two-step iteration (1.5) reduces to the Mann iteration (1.1) when $S=I$ and $b_{n}^{\prime}=0$.

(ii) The new modified two-step iteration (1.5) when $S=I$ reduces to the Ishikawa iteration (1.2).

(iii) The new modified two-step iteration (1.5) when $S=T$ reduces to the Agarwal et al. iteration (1.4). 
Let $K$ be a nonempty convex subset of a normed space $\mathrm{E}$ and $T: K \rightarrow K$ be a mapping, $F(T)=\{\rho \in K: T \rho=\rho\}$ is the set of fixed point of $\mathrm{T}$.

Definition 1.1 [13]. The map $T: E \rightarrow E$ satisfies condition $Z$ (Zamfirescu condition) if and only if there exist the real numbers $a, b, c$ satisfying $0<a<1,0<b, c<\frac{1}{2}$ such that for each pair $x, y \in E$ at least one condition is true:
i. $\quad\left(z_{1}\right)\|T x-T y\| \leq a\|x-y\|$
ii. $\quad\left(z_{2}\right)\|T x-T y\| \leq b(\|x-T x\|+\|y-T y\|)$,
iii. $\quad\left(z_{3}\right)\|T x-T y\| \leq c(\|x-T y\|+\|y-T x\|)$

An operator T satisfying the contractive conditions $\left(z_{1}\right),\left(z_{2}\right)$ and $\left(z_{3}\right)$ in the above theorem is called Zamfirescu operator (alternatively, we shall say that $\mathrm{T}$ satisfies condition $\mathrm{Z}$ ).

Berinde [4] introduced a new class of operators on an arbitrary Banach space E satisfying

$\|T x-T y\| \leq \delta\|x-y\|+2 \delta\|T x-x\|$

for any $x, y \in E, 0 \leq \delta<1$. He proved that this class is wider than the class of Zamfiresu operators and used the Ishikawa iteration process to approximate fixed points of this class of operators in an arbitrary Banach space.

If $(E, F-n o r m)$ is a complete metrizable topological vector space [1], then (1.6) becomes

$F(T x-T y) \leq \delta F(x-y)+2 \delta F(T x-x)$

for any $x, y \in E, 0 \leq \delta<1$.

Yildirim et al. [12], considered a new two-step iterative scheme for approximating fixed points of quasi-contractive operators and then, show that the Krasnoselskij, Mann, Ishikawa and a new two-step iterations are equivalent for quasi-contractive operators satisfying Zamfirescu operators.

Recently, Hussain et al. [5] established a general theorem to approximate fixed points of quasi-contractive operators in a Banach space through the iteration process due to Agarwal et al. [2]. Their result generalizes and improves the results of Babu and Prasad [3] and Berinde [4]. They also gave an example using a theoretical concepts to show that the iteration process due to Agarwal et al. [2] is faster than the Mann iteration process and the Ishikawa iteration process for Zamfirescu operators.

A natural question that arises is: Which of these iterations mentioned above converges faster for the class of quasi-contractive operators? It is the purpose of this paper to answer this question.

Firstly, we shall prove a strong convergence of the iteration process (1.5) to a fixed point of quasi-contractive operators.

\section{CONVERGENCE ANALYSIS}

Lemma 2.1 [2]. If $\alpha$ is a real number such that $0 \leq \alpha<1$, and $\left\{\varepsilon_{n}\right\}_{n=0}^{\infty}$ is a sequence of positive numbers such that $\lim _{n \rightarrow \infty} \varepsilon_{n}=0$, then for any sequence of positive numbers $\left\{a_{n}\right\}_{n=0}^{\infty} \quad$ satisfying $a_{n+1} \leq \alpha a_{n}+\varepsilon_{n}, n \geq 0$ we have $\lim _{n \rightarrow \infty} a_{n}=0$.

Theorem 2.2. Let $\mathrm{K}$ be a nonempty closed convex subset of a complete metrizable topological vector space E, and $T, S: K \rightarrow$ $K$ a selfmap of $K$ satisfying (1.7). Let $\left\{x_{n}\right\}_{n=0}^{\infty}$ be defined through the iterative process (1.5) and $x_{0} \in K$, where $\left\{b_{n}\right\}_{n=0}^{\infty}$ and $\left\{b_{n}^{\prime}\right\}_{n=0}^{\infty}$ are sequences of positive numbers in $[0,1]$ satisfying $\sum_{n=0}^{\infty} b_{n}=\infty$. Then, the modified two-step iteration method (1.5) converges to the fixed point of $T, S$.
Proof. Assume that $F(T \cap S) \neq \varnothing$ and $\rho \in F(T \cap S)$, then using (1.5), we have

$$
\begin{aligned}
F\left(x_{n+1}-\rho\right) & =F\left(\left(1-b_{n}\right) S x_{n}+b_{n} T y_{n}-\left[\left(1-b_{n}\right)+b_{n}\right] \rho\right) \\
& =F\left((1-b n)\left(S x_{n}-\rho\right)+b_{n}\left(T y_{n}-\rho\right)\right) \\
& \leq\left(1-b_{n}\right) F\left(S x_{n}-\rho\right)+b_{n} F\left(T y_{n}-\rho\right) .
\end{aligned}
$$

Now using (1.7) with $x=\rho, y=x_{n}$, and then with $x=\rho$, $y=y_{n}$, we obtain the following two inequalities,

$$
\begin{aligned}
F\left(S x_{n}-\rho\right) & \leq \delta F\left(x_{n}-\rho\right)+2 \delta F(T \rho-\rho) \\
& =\delta F\left(x_{n}-\rho\right),
\end{aligned}
$$

and

$$
\begin{aligned}
F\left(T y_{n}-\rho\right) & \leq \delta F\left(y_{n}-\rho\right)+2 \delta F(T \rho-\rho) \\
& =\delta F\left(y_{n}-\rho\right) .
\end{aligned}
$$

By substituting (2.2) and (2.3) in (2.1), we obtain

$$
\begin{aligned}
F\left(x_{n+1}-\rho\right) & \leq\left(1-b_{n}\right) \delta F\left(x_{n}-\rho\right)+b_{n} F\left(y_{n}-\rho\right) \\
& \leq\left(1-b_{n}\right) F\left(x_{n}-\rho\right)+b_{n} F\left(y_{n}-\rho\right) .
\end{aligned}
$$

In a similar fashion, again by using (1.6), we can get

$F\left(y_{n}-\rho\right) \leq\left(1-(1-\delta) b_{n}^{\prime}\right) F\left(x_{n}-\rho\right)$.

From (2.4) and (2.5), we have

$$
\begin{aligned}
F\left(x_{n+1}-\rho\right) & \leq\left[1-(1-\delta) b_{n}\left(1+\delta b_{n}^{\prime}\right)\right] F\left(x_{n}-\rho\right) . \\
& \leq\left[1-(1-\delta) b_{n}\right] F\left(x_{n}-\rho\right) .
\end{aligned}
$$

Using the fact that $0 \leq \delta<1$ and $0 \leq b_{n} \leq 1$. It is clear that $0 \leq\left[1-(1-\delta) b_{n}\right]<1$,

and by Lemma 2.1, it results that $F\left(x_{n+1}-\rho\right)=0$. Consequently, $x_{n} \rightarrow \rho$.

This completes the proof

Remark 2.3. Results using the iterative processes (1.1) - (1.4) can now be obtained as corollaries from Theorem 2.2.

\section{Numerical Example}

We give some examples to illustrate the efficiency of the iterative method (1.5) proposed in this paper. We compare this method with those existing in the literature. We use the following:

Let the map $T: E \rightarrow E$ be given by

$T x=\frac{x}{2}, \quad S x=\frac{x}{4}, \quad, \forall x \in E$.

Then the following can easily be verified:

(i) $T, S$ are Zamfirescu operators.

(ii) $F(T) \cap F(S)=\{0\}$.

Numerical computation have been carried out using a Java programme. The results are presented in Tables 1-3 with initial guess $x_{0}=x_{16}=0.5, \quad b_{n}=b_{n}^{\prime}=\frac{4}{\sqrt{n}}$. 
Table 1: Numerical Results of Iteration taking $\varepsilon=$ 0.000011

\begin{tabular}{|c|c|c|c|}
\hline $\begin{array}{c}\text { Iter. } \\
\text { Scheme }\end{array}$ & $\begin{array}{c}\text { Nos. } \\
\text { Iter. }\end{array}$ & $\begin{array}{c}\text { Covergence } \\
\text { Obtained }\end{array}$ & $\begin{array}{c}\text { Runtime } \\
\text { (nanotime) }\end{array}$ \\
\hline$(1.1)$ & 37 & $9.89525260342 \mathrm{E}-6$ & 6252471 \\
\hline$(1.2)$ & 27 & $6.34118355455 \mathrm{E}-6$ & 4001835 \\
\hline$(1.3)$ & 25 & $1.030640255097 \mathrm{E}-5$ & 3871372 \\
\hline$(1.4)$ & 25 & $8.54442892718 \mathrm{E}-6$ & 3665340 \\
\hline$(1.5)$ & 25 & $3.98518233229 \mathrm{E}-6$ & 3624902 \\
\hline
\end{tabular}

We consider a case when the threshold $\varepsilon$ is 0.000011 .

Table 2: Numerical Results of Iteration taking $\varepsilon=$ 0.0000011

\begin{tabular}{|c|c|c|c|}
\hline $\begin{array}{c}\text { Iter. } \\
\text { Scheme }\end{array}$ & $\begin{array}{c}\text { Nos. } \\
\text { Iter. }\end{array}$ & $\begin{array}{c}\text { Covergence } \\
\text { Obtained }\end{array}$ & $\begin{array}{c}\text { Runtime } \\
\text { (nanotime) }\end{array}$ \\
\hline$(1.1)$ & 43 & $9.91500800067 \mathrm{E}-7$ & 9132864 \\
\hline$(1.2)$ & 27 & $6.96203690098 \mathrm{E}-7$ & 4790274 \\
\hline$(1.3)$ & 25 & $5.18522612999 \mathrm{E}-7$ & 4322267 \\
\hline$(1.4)$ & 25 & $1.005613558352 \mathrm{E}-6$ & 4045906 \\
\hline$(1.5)$ & 25 & $3.3777725805 \mathrm{E}-7$ & 3982629 \\
\hline
\end{tabular}

We also consider a case when the threshold $\varepsilon$ is 0.00000011 .

Table 3: Numerical Results of Iteration taking $\varepsilon=$ 0.00000011

\begin{tabular}{|c|c|c|c|}
\hline $\begin{array}{c}\text { Iter. } \\
\text { Scheme }\end{array}$ & $\begin{array}{c}\text { Nos. } \\
\text { Iter. }\end{array}$ & $\begin{array}{c}\text { Covergence } \\
\text { Obtained }\end{array}$ & $\begin{array}{c}\text { Runtime } \\
\text { (nanotime) }\end{array}$ \\
\hline$(1.1)$ & 50 & $8.5721045946 \mathrm{E}-8$ & 9283233 \\
\hline$(1.2)$ & 33 & $9.31744543145 \mathrm{E}-8$ & 9233575 \\
\hline$(1.3)$ & 30 & $7.928081255214 \mathrm{E}-8$ & 5418565 \\
\hline$(1.4)$ & 30 & $4.575349044423 \mathrm{E}-8$ & 5237258 \\
\hline$(1.5)$ & 28 & $9.94085028675 \mathrm{E}-8$ & 4311302 \\
\hline
\end{tabular}

Tables 1-3 show that the new modified two-step iterative method (1.5) is more efficient than the other iterations (1.1)(1.4) in terms of number of iterations to be carried out before convergence and the execution time. It could be observed that as the threshold $\varepsilon$ tends to zero, iteration (1.5) converges faster to the fixed point than all the other iterative methods (1.1)- (1.4).

\section{REFERENCES}

[1] N. Adaschl, B. Ernst, D. Kleim, Topological Vector Spaces, Springer- Verlag, ( 1978).

[2] R.P. Agarwal, D. O'Regan, D.R. Sahu , Iterative construction of fixed points of nearly asymptotically nonexpansive mappings, J Nonlinear Convex Anal. 8 2007)(1), 61-79.

[3] GVR. Babu, KNVVV. Prasad, Mann iteration converges faster than Ishikawa iteration for the class of Zamfirescu operators, Fixed Point Theory Appl, ( 2006), 1-6 . Article ID 49615.

[4] V. Berinde, On the stability of some fixed point procedures, Bul. Stiint. Univ. Baia Mare, Ser. B, Matematica-Informatica, xviii: ( 1974), 7- 14.

[5] N. Hussain, A. Rafiq, B. Damjanovi and R. Lazovi, On rate of convergence of various iterative schemes, Fixed Point Theory and Applications , 45( 2011), 1-6.

[6] S. Ishikawa, Fixed points by a new iteration method, Proc. Am. Math. Soc. 44 ( 1974), 147-150.

[7] W. R. Mann, Mean Value methods in iteration, Proc. Am. Math. Soc. 4 ( 1953), 506-510.

[8] J.O. Olaleru, A comparison of Picard and Mann iterations for quasi-contractive maps, Fixed point theory, Vol. 8, No. 1 ( 2007), 87-95.

[9] J.O. Olaleru and A.A. Mogbademu, On the stability of some fixed point iteration procedures with errors, Boletino de la Asociacion Matematica Venezolana, Vol. XVI, No. 1 ( 2009), 31-37.

[10] M.O. Olatinwo and C.O. Imoru, On some stability results for fixed point iteration procedure, Journal of Math. and Stat. 2(1), ( 2006), 339-342 .

[11] B.E. Rhoades, Fixed point theorems and stability results for fixed point iteration procedures I, Indian J. Pure and Applied Math., 21, ( 1990), 1-9 .

[12] I. Yildirim, M. Ozdemir and H. Kiziltun, On the Convergence of a New Two-Step Iteration in the Class of Quasi-Contractive Operators, Int. Journal of Math. Analysis, Vol. 3, ( 2009), no. 38, 1881 - 1892.

[13] T. Zamfirescu, Fixed point theorems in metric spaces, Archiv der Mathematik. 23, (1992), 292-298. 